\title{
Insulin adjustment
}

National Diabetes Information Clearinghouse (NDIC)

\section{Definitions}

Insulin

Defined by National Diabetes Information Clearinghouse (NDIC)

Diabetes

Defined by National Diabetes Information Clearinghouse (NDIC)

Blood glucose level

Defined by National Diabetes Information Clearinghouse (NDIC)

\section{Source}

National Diabetes Information Clearinghouse (U.S.). (2009). The diabetes dictionary. [Bethesda, Md.]: U.S. Dept. of Health and Human Services, National Institutes of Health, National Institute of Diabetes and Digestive and Kidney Diseases, National Diabetes Information Clearinghouse.

A change in the amount of insulin a person with diabetes takes based on factors such as meal planning, physical activity, and blood glucose levels. 